\title{
As Aventuras de Per Gynt
}

Francis Henrik Aubert Yuri Fabri Venancio

Peter Christen Asbjørnsen nasceu em Christiania (hoje Oslo) em 1812. Seu pai era vidraceiro e possuía uma oficina em que aprendizes e viajantes se reuniam para conversar e contar os "causos" e acontecimentos, permitindo ao pequeno escritor que desde cedo já tivesse contato com a narrativa oral popular.

Junto com seu amigo e colega de ginásio Jørgen Engebretsen Moe, Asbjørnsen publicou uma grande quantidade de livros contendo contos e relatos orais regionais do imaginário norueguês. A principal façanha desses dois escritores na construção da identidade nacional foi conseguir transpor essas narrativas locais para o plano da literatura norueguesa ainda em formação. Para que isso fosse possível, todos aqueles registros orais tiveram que ser convertidos do dialeto do narrador para o riksmål (dano-norueguês), língua oficial falada por toda a classe dirigente, pois a Noruega naquela época não dispunha de um idioma oficial e unificado genuinamente norueguês. As adaptações de conteúdo para o texto traduzido a fim de agradar todas as camadas sociais também foram um grande desafio, visto que relatos orais populares normalmente não possuem restrição ou censura nas palavras nem nas próprias informações contidas. Em pouco tempo, esses materiais passaram a ser inseridos nos livros didáticos escolares, competindo com os textos religiosos e filosóficos dominantes nas épocas anteriores. O escritor Sigurd Hoel também comenta que a literatura de Asbjørnsen e Moe é a obra literária do século retrasado que mais trouxe diversidade e grandeza para o sentimento e autorreconhecimento nacional (BØ, 2006, pp. 75-77).

1 Extraídas da $2^{a}$ edição de Norske Huldre-Eventyr og Folkesagn, de P. Ch. Asbjørnsen. 
Dentre os registros orais coletados e publicados por Asbjørnsen encontram-se as "estórias" ou "causos"; em norueguês, sagn. Segundo Bø (op. cit, p. 87), uma das principais características desse gênero é conter uma estrutura textual composta por molduras (frames) relativamente fixas e recorrentes Utilizando-se delas, a estória é iniciada e concluída por meio de um relato de como um narrador em primeira pessoa pôs-se a presenciar uma "situação folclorística primária", em que um ou vários "causos" são contados por um ou mais narradores e, ademais, tais frames também possibilitam a caracterização do ambiente em que essa "situação folclorística primária" ocorre, ou seja, esse ambiente é representado como um cenário naturalmente possível para que um círculo seja formado a fim de narrar as estórias de outrora. Outra característica desse gênero é a anonimidade do narrador em primeira pessoa, que geralmente representa a classe de escolaridade avançada, capaz de garimpar e anotar esses "causos"; porém, em várias dessas narrativas, fica-se com a impressão de que esse narrador é o próprio Asbjørnsen, que, como já sabido, viajava pela Noruega buscando resgatar as múltiplas tradições orais. O trecho aqui traduzido causa essa impressão, pois, historicamente, Asbiørnsen viajou de fato com um caçador inglês para o Vale de Gudbrand, local onde a estória acontece e, na narrativa, há um inglês junto ao narrador em primeira pessoa. No trecho selecionado, entretanto, o narrador em primeira pessoa não demonstra qualquer tipo de opinião sobre a credibilidade dos "causos", ao passo que o narrador do "causo" acredita que tudo não passa de invencionices da fantasia popular.

A tradução aqui oferecida foi feita a partir de um trecho retirado de um relato mais amplo chamado Hoyfjellsbilleder ${ }^{2}$, publicado pela primeira vez em 1848 no segundo volume de um livro chamado Norske Huldre-Eventyr og Folkesagn ${ }^{3}$. O relato se divide em dois capítulos, En sondagskveld til saters ${ }^{4}$ e En rensdyrjakt $i$ Rondane ${ }^{5}$ e, historicamente, foi construído a partir de memórias e recordações da viagem que Asbjørnsen fez a Gudbrandsdalen em 1842 junto com esse caçador inglês, já citado, mais especificamente para um sítio em Høvringen, na freguesia de Sel. O trecho traduzido ocupa-se dos "causos" relativos a Per Gynt e integra o segundo capítulo, que narra o dia seguinte da estória contida no primeiro capítulo, quando as personagens (o narrador, o inglês John Tottenbroom, Anders e Tor Ulsvollen) adentram as montanhas para caçar renas e se abrigam em uma pequena cabana

\footnotetext{
Em uma tradução aproximada, Imagens das Montanhas Altas.

Em uma tradução aproximada, Contos de Encantados e do Folclore Norueguês.

Em uma tradução aproximada, Uma noite de domingo em uma choupana de pastor.

Em uma tradução aproximada, Uma caçada à rena na região de Rondane.
} 
de pedra pertencente a uma figura chamada Per Fuggelskjellé (propriamente, "Pedro Escama de Pássaro"). Essa situação gera uma ambientação que permite que tais estórias sobre trolls, encantamentos e caçadores, como Per Gynt, sejam contadas. As peripécias de Per Gynt, na realidade, foram coletadas por Asbjørnsen nessa mesma viagem a Sel por meio de um informante de quinze anos chamado Engebret Hougen, falante do dialeto vågaimål (do norte do Vale de Gudbrand), que se tornaria um renomado diretor de escola, escritor e contador de estórias por possuir uma vasta memória para contos, "causos" e assuntos folclóricos. Entretanto, na estória, esse trecho é narrado por Per Fuggelskjellé, que fora solicitado pelo narrador a contar uma estória qualquer e, a partir daí, essa personagem começa a narrar os relatos antigos sobre as alegadas aventuras de Per Gynt.

$\mathrm{Na}$ versão em português, os relatos foram divididos por subtítulos, para que o leitor pudesse melhor compreender o momento em que um relato começa e termina: de certa forma, cada episódio se entrelaça ao próximo, tecendo uma mesma imagem de um caçador corajoso e teimoso que enfrenta e derrota os trolls, superando as magias destes por meio de artimanhas e, por vezes, trapaças. Quanto ao idioma, como Asbjørnsen procurava dar voz a seus contadores de estória, os relatos estão escritos originalmente no dialeto da região em que cada um foi coletado, ou seja, no dialeto do norte de Gudbrandsdalen, o vågåmål e, por isso, além de ser uma obra relevante para fins culturais e literários noruegueses, também é um importante registro linguístico. Contudo, a narração em primeira pessoa (ou seja, a voz de Asbjørnsen) não está escrita em dialeto. Não houve a intenção de fazer uma tradução do dialeto vågåmål para uma fala regional brasileira, pois não há relações culturais, nem paralelismos geográficos ou históricos que permitam uma aproximação entre os dialetos que fosse ao menos verossímil.

A importância do texto aqui oferecido à tradução prende-se, de um lado, a todo o processo de formação da identidade cultural e linguística da Noruega, que se estende desde os últimos decênios da Dupla Monarquia (Dinamarca/Noruega) até, praticamente, o início do século XX (1905 - com o fim da união pessoal com a Suécia - e além). De outro, é este "causo" que, seja na versão de Asbjørnsen, seja por outros e paralelos caminhos (OLIVEIRA E SILVA, 2012) deu origem ao "poema dramático" Peer Gynt, uma das obras-primas de Henrik Ibsen (1867). É nossa convicção que a familiaridade com este relato do folclore norueguês poderá contribuir com chaves de leitura relevantes para a obra de Ibsen e sua visão crítica, por vezes amarga, de seus concidadãos.

De Kiel a São Paulo, junho de 2012 


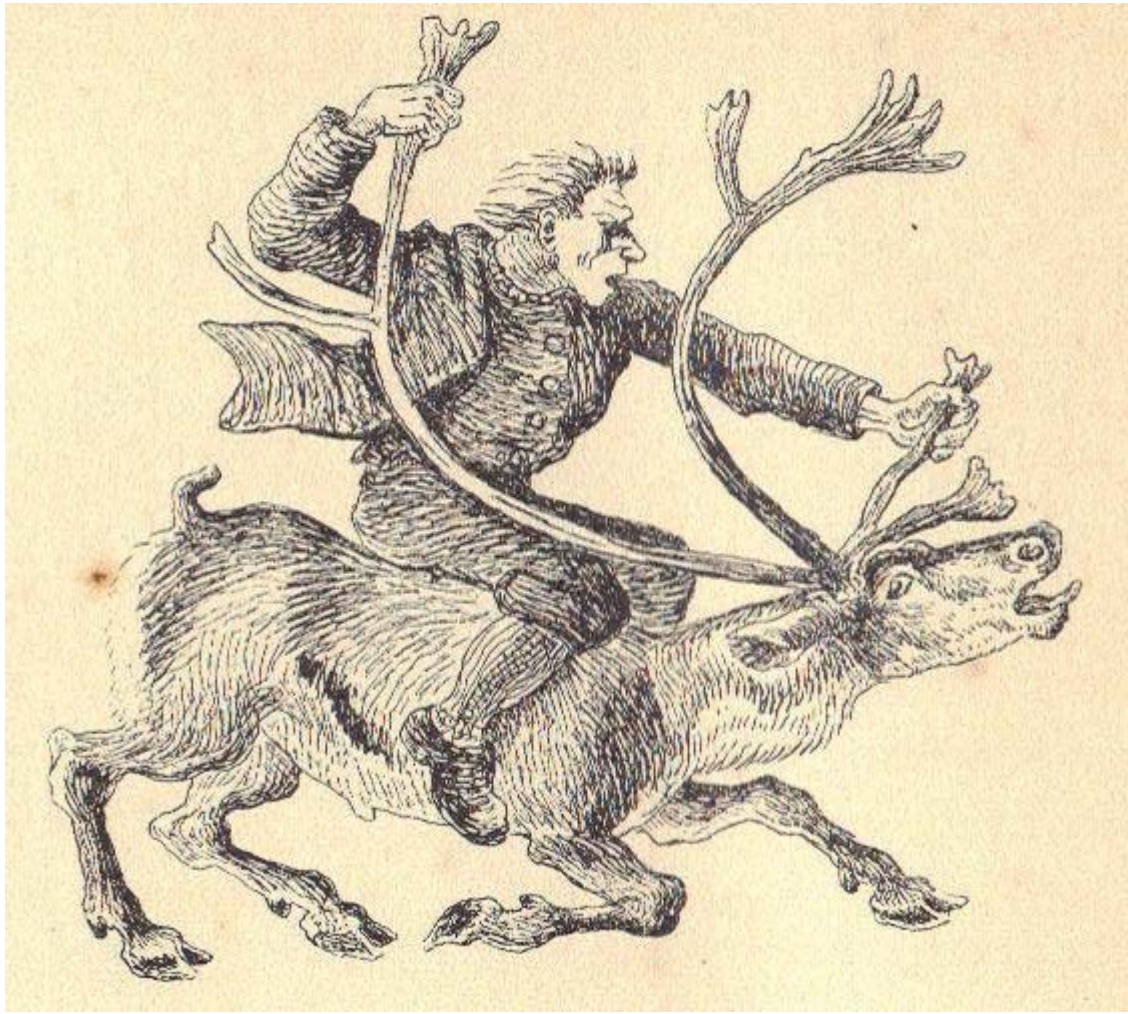

Ilustração de Ridley Yngvar Borchgrevink.

HØYFJELLSBILLEDER

II

Rensdyrjakt Ved Rondane

$(\ldots)$

Det var ein skyttar i Kvam i gamle dågå," begynte han, "og han heitte Per Gynt. Han låg støtt inni fjellé, og der skaut 'n både bjønn og elg -for i di ti'om va det meire skog på fjellé, der heldt det til, slikt ofryskjé.

\section{IMAGENS DAS}

ALTAS MONTANHAS

II

Uma caçada à rena na região de Rondane

$(\ldots)$

Há muitos e muitos anos havia em Kvam um caçador chamado Per Gynt, que costumava vagar pelas montanhas, onde caçava alces e ursos, pois naquela época as florestas eram mais extensas e o que não faltava era bicho de todo tipo. 


\section{Per Gynt e o Curvo ${ }^{6,7}$}

Så va det eingong seint på hausten, lenge etter buferdstid, at ' $n$ Per skull åt fjellé. Alt folke va heimatt-reist tå fjellé, så nære som tri budeio.

Da han kom upp imot Høvringen, - for der skull han væra i ei seter um natté, - va det så myrkt at han kunn ikkje sjå ei hånd for seg, og hunden tok til å stor-søkje så det va reint spøkjé. Rett som det va, kom han innpå nogo, og da han tok burtpå det, va det både kaldt og sleipt og stort. Han trudde ikkje han va komen av vegen heller, så han kunne ikkje veta kå det va; men ohoglé va det.

"Kæm æ detta?" sa 'n Per, for han kjende det røyrde på seg.

“A, dæ æ den store Bøygen,” svårå det.

Men det va 'n Per Gynt like klok, måta; men han gjekk utmed det eit stykkje, "for en sta'n lyt e fel komå fram," tenkte 'n. Best det va, kom 'n innpå nogo att, og da han tok burt på det, va det både stort og kaldt og sleipt.

"Kæm æ dæ?" sa 'n Per Gynt.

“Å, dæx Bøygen,” svårå det att.

"Ja, anten du $x$ rett hell bògjé, så lyt du sleppe meg fram," sa 'n Per, for han skjønte at han gjekk i rund ring, og at Bøygen hadde ringa seg um selé. Dermed så le’a Bøyg litt
Foi num final de outono, a época do pastoreio tinha terminado já fazia muito tempo, que Per decidiu ir p'ras montanhas. Quase todo mundo já tinham retornado de lá, fora três pastoras.

Quando ele chegou ao alto de Høvringen junto à cabana em que passaria a noite, estava tão escuro que ele mal conseguia ver a própria mão, e seu cachorro começou a fuçar por todos os lados como se estivesse à procura de algo. Parecia coisa de assombração. De repente, Per esbarrou em algo e ao passar a mão, percebeu que era frio, liso e grande. Como não achava que tivesse se perdido, ficou sem saber do que se tratava, mas que era assustador lá isso era.

- Quem vai aî? - indagou Per, porque ele sentiu a coisa se mexer.

- Ora, sou eu, o Curvo!- respondeu a coisa. Com essa resposta, Per Gynt ficou na mesma, pode crer; mas seguiu em frente por mais um trecho "porque de um jeito ou outro eu chego lá!”, pensou. De repente, esbarrou novamente em uma coisa e, ao apalpar, sentiu que era algo grande, frio e liso.

- Quem é?- perguntou o rapaz.

- Ora, sou eu, o Curvo! - veio de novo a resposta.

- Tanto se me dá! Deixa eu passar - disse Per, pois percebeu que estava andando em círculos e que a estranha criatura havia cercado a cabana por inteiro; de repente, a

6 N. dos T.: No original, Bgygen. O sentido do termo inclui "curvatura", "elasticidade", "flexibilidade”. Em algumas encenações da peça Peer Gynt, de Henrik Ibsen, em que o Bøygen desempenha um papel de relevância, é representado por uma névoa espessa. Na mitologia popular, é representado como uma serpente de proporções gigantescas.

$7 \quad$ N. dos T.: Subtítulos inseridos para facilitar a leitura. 
på seg, så vidt at 'n Per kom fram åt selé. Da 'n kom inn, va det ikkje ljosare der hell ute, og han fór og fomla ikring veggjene og skull setja frå seg børsa og leggje ned skreppa; men best han gjekk og trevla seg fram, kjende ' $n$ detta kalde og store og sleipe att.

“Kæm æ dæ?" ropte 'n Per Gynt.

“Å, dæ æ den store Bøygen,” svårå det.

Og kor han tok, og kor han bau te å gå, så kjende 'n ringen tå Bøygjé. "Her æ dæ nok ikkje godt å væra," tenkte Per Gynt, "sia denne Bøygen $x$ både ute og inne; men e ska fel skjepa på denne tverrbleggen!” Så tok 'n børsa og gjekk ut att, og trevla seg fram til han fann skallin på 'om.

“Kå æ du for ein?” sa 'n Per.

“Å, e æ den store Bøygen i Ætendalé," sa stortrølle. Så gjorde 'n Per Gynt bråfang og skaut tri skot i hugue på det.

"skjot eitt te!" sa Bøygen.

Men han Per visste bæ're, for hadde 'n skote eitt te, hadde det gått attende på 'n sjøl. Dermed tok døm i, både han Per og hundan, og dro stortrølle ut, så døm kunne komå væl inn i selé. Mea skratta og log det rundt $i$ alle haugan:

"Per Gynt drog mykjy, men hondæin drog meir," sa det. coisa moveu-se um pouquinho e o rapaz mal conseguiu atravessar e passar pela porta. Lá dentro estava tudo tão escuro quanto o lado de fora, e Per ficou a zanzar e tatear as paredes. E no momento em que estava para colocar a carabina e a mochila no chão, sentiu novamente aquela coisa fria, grande e lisa.

- Quem é que ‘tá aí? - perguntou Per Gynt.

- Ora, sou eu, o Grande Curvo! - respondeu a coisa.

Por onde quer que Per fosse ou tocasse, ele sentia a presença do Curvo, que o circundava como um anel. "Aqui não é um bom lugar pra ficâ", pensou ele, “já que este Curvo está tanto dentro como fora da cabana. Vou dar um jeito nessa criatura teimosa!". Per pegou sua carabina e saiu novamente para tentar encontrar a cabeça da criatura.

- Quem é você, seu coisa?

- Ora, sou eu, o Grande Curvo de Etnedal - disse o grande troll. Per rapidamente disparou três tiros em sua cabeça.

- Atire mais uma vez! - disse o Curvo.

Mas Per, que não era tolo nem nada, logo percebeu que se atirasse mais uma vez a bala voltaria certeiramente para ele mesmo. Então Per e seu cachorro empurraram o Grande Curvo para fora para que pudessem ficar sossegados dentro da cabana. Enquanto isso ouviam-se vozes e gargalhadas por todos os cantos das colinas e montanhas:

- Per empurrou bastante, mas os cachorrinhos dele empurraram bem mais! 


\section{Per Gynt e Gyri Cara-de-Sopa}

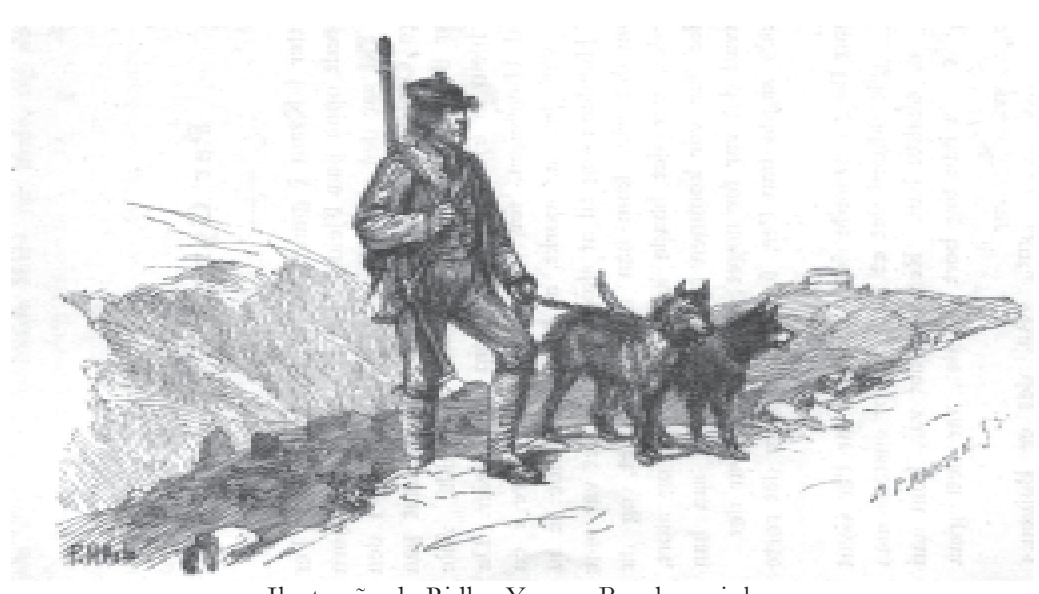

Ilustração de Ridley Yngvar Borchgrevink.

Om morgon skull 'n ut og veida dyr. Da han kom inn i fjelle, fekk ' $n$ sjå ei førkje som lokka fenæin over Tverrhø. Men da 'n kom dit upp, var gjenta burte, og fenæin au; han såg ikkje anne helle ein stor hop med bjønn.

"Nå ha e aldri sett bjønn hopa seg førr," tenkte 'n Per ved seg sjøl; men da 'n kom nærmare, va døm burte alle sammen, umframt ein.

Så hua det i ein haug borti der:

"Akte galtin din

Per Gynt a ute

ma svansen sin!"
Ao amanhecer, Per saiu para caçar. Assim que se adentrou nas montanhas, avistou uma pastora que tangia as vacas bem ao longe na direção de Tverrhø. Mas, quando chegou lá em cima, ele percebeu que tanto ela quanto o gado haviam desaparecido; e que havia apenas um grupo de ursos no local.

Per pensou com seus botões: "nunca vi urso de manada". E quando se aproximou, percebeu que só havia um urso, todos os outros também haviam desaparecido.

E se ouviu das colinas:

\section{"Proteja o seu leitão \\ Per Gynt está à solta \\ Com seu rabicó!"}

“ $\AA$, dæ bli oheppe for ' $n$ Per, men ikkje for - Oh, o azar é do Per, mas não do meu

8 N. do T.: Na mitologia norueguesa, um indivíduo com cauda poderia parecer ser gente, mas era na realidade um ser encantado (um bulder, uma versão mais antropomórfica do troll.) 
galtin min, for han ha ikkje tvætta idag," sa det $i$ haugen.

Han Per vaska nevan sine i det vatne han hadde, og skaut bjønnen. Da log og skratta det $i$ haugen.

“Du kunn akta galtin din!" ropte det.

"E kom ikkje i hog han ha vasskoppen imillom føtom," svårå den andre.

Per flådde bjønnen og grov skrotten ned i uré, men skallin og skinne tok ' $\mathrm{n}$ med seg. På heimvegen trefte 'n ein fjellrakke.

"Sjå lammet mitt, kå feitt dæ går," sa det burti ein haug.

"Sjå svansen hass Per, kå høgt 'n står," sa det $\mathrm{i}$ ein annen haug, da 'n Per la rifle åt augaé og skaut 'n.

Den flådde 'n og tok med seg, og da han kom åt seteren, sette 'n hugué utafor med gapande kjeft. Så gjorde 'n upp varme og sette på ei supgryte. Men det rauk så reint orimelé at han va mest ikkje god te halde augun uppe, og derfor laut 'n læta upp ein gluggje som va der. Best det va, kom det eit trøll og stakk inn gjenom gluggin ein nåså så lang at 'n rokk burti skorstein'

“Her ska du sjå snythøinn!” sa det.

“Her ska du kjæinne supkøinn!" sa 'n Per Gynt, og auste heile supgryta over nåsan på det.

Trølle avsted og bar seg ille; men rundt $\mathrm{i}$ alle haugom skratta og log det og ropte:

“Gyri Suptryne, Gyri Suptryne!” leitão, pois ele não se lavou hoje. - ouviuse das colinas.

Per lavou seus punhos na água que tinha e atirou no urso. E ouviam-se novamente vozes e gargalhadas:

- Você deveria cuidar melhor do seu leitãozinho - gritou alguém.

- Eu não reparei que ele 'tava com catapora entre os pés - respondeu o outro.

Per esfolou o urso, pegou a pele e a cabeça para si e enterrou o resto na charneca. No caminho de volta pra casa, ele também trombou com uma raposa-do-ártico.

- Veja meu carneirinho, como está gordinho - ouviu-se de uma colina.

- Veja o rabinho de Per, como está todo empinado - ouviu-se de outra colina, quando Per pôs a carabina na mira e matou a raposa com um tiro só.

Assim que esfolou o animal, Per voltou para a cabana levando consigo sua pele e pendurou a cabeça boquiaberta no lado de fora. Assim que entrou, acendeu o fogo e pôs um caldeirão para fazer sopa. Mas a fumaça era tanta que mal dava para ficar de olhos abertos, e então Per abriu um alçapão que havia no teto. De repente, apareceu uma troll que meteu pelo buraco do alçapão um nariz tão comprido que chegava até a lareira.

- Olha aqui meu focinho! - disse a troll.

- Sinta aqui minha sopa! - disse Per, que derramou toda a sopa no nariz dela.

A troll foi embora fazendo um escarcéu. E pelas colinas ouviam-se vozes e gargalhadas que diziam:

- Gyri Nariz-de-Sopa! Gyri Nariz-de-Sopa! 


\section{Per Gynt e as três pastoras}

Nå va det stilt ei stund; men det vara ikkje lengje før det vart ståk og styr att utafor. Han Per såg ut, og der såg 'n ei vogn med bjønne for; døm væla upp stortrølle og reiste inn i fjelle med 'om.

Best det va, kom det ei vassbytte ned gjenom pipa og sløkte varmin, så 'n Per vart sitjan’ der i myrkre. Da tok det til å knitle og skratte i alle krokom, og så sa det:

"Nå ska dæ ikkje gå bæ're 'om Per hell me Vala-budeiom."

Så la 'n Per på varmin att, tok hunden, læste att selé og la nordetter åt Valsætrom, der di tri budeiun låg. Da han kom eit stykkje nordpå, brann det slik der, som Valsætrin skull stå i ljos logå. Med det såmå trefte 'n ein hop med ulve, og nogre tå døm skaut 'n og nogre slo 'n ihæl. Da han kom åt Valsætrom, va det kolmyrkt der og ingen brånå; men det va fire fræmonde kare inne som heldt på med budeiom, og det va fire haugtrøll, og døm heitte Gust i Væré, Trond Valfjellé, Tjøstol Åbakka og Rolv Eldførpungjé.

Han Gust i Væré sto uttafor døré og skull halde vakt, me di andre va sjå budeiom og fridde. Han Per skaut etter 'om, men råkå ikkje, og så reiste 'n Gust i Væré. Da 'n Per kom inn, ståka døm stygt med budeiom, og tvo tå gjentom va reint vetskræmde og ba gud hjòlpe seg; men den tridje, som heitte Gæiln-Kari, va ikkje redd; døm kunne gjerne komå, sa ho; ho kunne nok ha hog te sjå om det va tô i slike kare.
E por algum tempo fez-se silêncio. Mas não demorou muito para que se ouvisse uma grande fuzarca do lado de fora. Quando Per foi espiar, viu uma carruagem puxada por ursos, que pegou o grande troll e o levou para dentro das montanhas.

De repente, um balde de água desceu pela chaminé e apagou o fogo da lareira de Per, que ficou num breu total. Gargalhadas e rangidos se ouviam por todos os cantos, até que uma voz lhe disse:

- Vai se dar mal, assim como as pastoras de Val.

Per voltou a acender a lareira, pegou seu cachorro, fechou a cabana e foi rumo ao norte, para as Cabanas de Val, onde estavam as três pastoras. Após ter percorrido um trecho ao norte, ele avistou um grande incêndio, lá ao longe, como se as Cabanas de Val estivessem em chamas e ao mesmo tempo se deparou com uma matilha de lobos: atirou em alguns e matou outros. Ao chegar junto às Cabanas de Val era uma escuridão só e não havia incêndio algum; mas encontrou quatro estranhos que estavam de gracinha com as pastoras; eles eram quatro Trolls das Montanhas: Gust i Været, Trond Valfjellet, Tjøstol Åbakka e Rolv Eldførpungen.

Gust i Været estava de sentinela na porta da cabana enquanto os outros estavam fazendo a corte às moças. Per se aproximou do troll, mirou e atirou, mas a bala passou longe, e o Gust i Været saiu chispando. Ao abrir a porta, Per viu que duas pastoras estavam terrivelmente assustadas pedindo a Deus para ajudá-las. A outra pastora, KariDoida, que não demonstrava medo algum, disse que por ela podiam vir sempre, ela 
Men da trøllé skjønte at 'n Per va innkomin, begynte døm å bæra seg ille, og sa åt Eldførpungjé at 'n laut leggje på varmin. Med det såmå sette hundan på 'n Tjøstol og reiv 'n i koll i årin, så oska og eldmørja gauv ikring 'n.

"Såg du slangæin mine, du Per?" sa 'n Trond Valfjellé - det var ulvæin sine han kalla så.

"Nå ska du såmå veigen som slangæin dine," sa 'n Per og skaut 'n. Sia slo 'n Åbakkjin ihæl med børsekolven, men Eldførpungjen hadde reist upp igjenom pipa. er.

Da ' $n$ Per hadde gjort det, fylgde ' $n$ budeiom til bygdar, for døm torde ikkje væra der leng.

\section{Per Gynt e seu urso branco}

Men da det lei mot jul-leite, va 'n Per Gynt ute att. Han hadde høyrt um ein gard på Dovre, der det kom så fullt tå trøll kor julkveld at folket laut rømme av åt andre garde. Dit ville ' $\mathrm{n}$ for han va hoga etter trølldom. Han kledde seg ut riktogt stygg, og så tok 'n med seg ein tam kvitbjønn, og syl og bek og bustleiv. Da 'n kom dit, gjekk 'n inn i stugu og ba um hus. queria mesmo ver de que estofo esses caras eram feitos.

Quando os trolls perceberam que Per havia entrado na cabana, começaram a reclamar e pediram para que Rolv Eldførpungen colocasse mais lenha na lareira, mas Per percebeu a situação em que se encontrava e soltou o cachorro em cima de Tjølstol, que caiu dentro da lareira. Brasas e cinzas voaram sobre ele.

- Você viu minhas cobras, Per? - perguntou Trond Valfjellet, que chamava seus lobos de cobras.

- Pois você vai pro mesmo caminho que as suas cobras! - disse Per, e passou fogo no troll. Em seguida, com coronhadas, deu cabo do Ảbakka; enquanto isso, Eldførpungen desembestou pela chaminé afora.

Após toda essa confusão, Per levou as três camponesas, sãs e salvas, de volta a seus povoados, pois elas não tinham mais coragem de ficar naquele local.

Mas, quando as festas de fim-de-ano se aproximaram, Per saiu de novo para caçar. Ele tinha ficado sabendo de um sítio lá nas terras altas de Dovre, onde apareciam tantos trolls perto da Véspera de Natal que o pessoal de lá tinha que fugir para outros sítios. Como lhe agradava a idéia de reencontrar os trolls, Per se vestiu de trapos, pegou um canivete, um pouco de betume, uma agulha de sapateiro e um urso branco manso, e partiu para Dovre. Quando lá chegou, avistou uma cabana e pediu por abrigo: 
"Gud hjòlpe oss," sa mannen; "oss kann ikkje låne deg hus, oss lyte reise tå gardé sjølve, for kor einaste julkveld kjøm det så fullt med trøll her."

Men Per Gynt han meinte på det, han skull nok reinske huse for trøll, og så fekk 'n lov til å bli da, og fekk eit purkeskinn attpå.

Så la bjønnen seg bak omnen, og han Per tok fram bek, syl og bustleiv og sette seg te gjera ein stor sko tå heile purkeskinne. Han sette i eit sterkt reip til snøreband, så 'n kunne snurpe att skoen rundt ikring; eit par handspake hadde 'n også ferdoge.

Rett som det va, så kom døm, med fele og spelemann, og summe dansa og summe åt tå julkosté som sto på bordé; summe steikte flesk, og summe steikte frosk og padder og mykjy anna ofysé, - den julkosten hadde døm med seg sjølve.

Da fekk nogre sjå skoen han Per hadde gjort. Den, tykte døm, va åt ein stor fot; så skull døm freiste ' $n$, og da alle hadde sett uppi eine foten, så rykte ' $n$ Per te, og sette den eine handspakin $\mathrm{i}$ og bende te, så $\mathrm{d} ø \mathrm{~m}$ sat fast i skoen alle sammen. Men så stakk bjønnen nasan fram og lufta på steikjé.

"Vil du hå kurv, kvitpus?” sa eit tå trølldom, og kasta ein glosteikt frosk like i gape på 'om.
- Que Deus nos acuda! - disse o homem a gente não pode dar abrigo não, temos que dar o fora daqui! Toda Véspera de Natal isso aqui fica cheio desses trolls!

Mas Per Gynt disse que pretendia livrar o sítio de trolls e então deixaram que ele ficasse por lá, e ainda deram para ele uma pele de porco.

O urso foi deitar atrás do forno enquanto Per pegava o canivete, o betume e a agulha de sapateiro e se abancava para fazer um gigantesco sapato com toda a pele de porco. Costurando com um forte pedaço de corda que trazia consigo, ele completou o calçado. Ele também arranjou um par de bastões.

De repente, lá vieram eles, com rabeca e violeiro, alguns dançando e outros se servindo dos pratos típicos do Natal que já estavam dispostos sobre a mesa; outros fritavam porcos; e outros, ainda, fritavam sapos, rãs e outras coisas ainda mais nojentas - que eram pratos que eles mesmos haviam trazido para a ceia

Foi então que um dos trolls avistou o grande sapato que Per havia feito. Todos ficaram impressionados com o seu tamanho, e assim que um resolveu experimentar, todos os outros também quiseram por o pé nele, ao mesmo tempo. Quando todos os pés estavam dentro do sapato, o Per apertou o cadarço e lá enfiou um dos bastões, de modo que pudesse torcê-lo por todos os lados do sapato e, por fim, todos os Trolls se encontravam presos pelo pé. Foi então que o urso branco ergueu o focinho e sentiu o cheiro de assado.

- Quer uma salsicha, gatinho branco? disse um troll, que jogou um sapo tostado diretamente na boca do urso. 
"Klor og slå, bamse!" sa 'n Per Gynt. Så vart bjønnen så $\arg \mathrm{og}$ vill at 'n fór upp og slo og klora døm alle sammen, og 'n Per Gynt slo burti hopen med den andre handspakin, som um han ville slå inn skallin på døm, - den spakin hadde 'n firkløvd, så døm ikkje skull få rekna tå seg slagje.

Da laut trøllé rømme, og 'n Per vart væran der og livde væl tå julkosté heile helgjé.

Sia høyrde døm ikkje meir til trølldom på mange år. Men mannen hadde ei ulvsblakk merr, og den rådde 'n Per 'om til å setja på føl under, som kunne fara og kjæte seg ikring millom haugom der.

Så va det ved jul-leite mange år etter mannen va i skogen og hogg ved åt helgen; da kom det ut eit trøll og ropte åt 'om:

"Ha du dæin store kvitpausen din æinnå, du?"

“Ja, han ligg heime bak omn'," sa mannen, “og nå ha 'n fått sjau onge, mykjy større og argare hæill 'n $æ$ sjøl."

“Så kjøm oss æilder meir åt deg!" ropte trølle.

$$
* * * * *
$$

"Den Per Gynt va ein for seg sjøl," sa Anders; "han va riktogt ein æventyrkremar og røgle-smed du skull havt moro di tå; han fortælde støtt at han hadde voré med ti alle de historiom folk sa hadde hendt i gamle dågå."
- Ataque e arranhe, ursinho! - disse Per Gynt. O urso ficou tão bravo e fora de si que se levantou atacando e arranhando os trolls, que estavam presos em sua frente; ao mesmo tempo, Per batia com o outro bastão como se fosse esmigalhar-lhes as cabeças. Ele havia trincado o bastão em quatro lâminas para que os trolls não pudessem saber de onde viria o golpe.

Com isso tudo, os trolls saíram corridos e o Per ficou por lá, aproveitando a fartura natalina durante todo o feriado.

Desde então, e por muitos Natais, não se ouviu mais falar de trolls por aquelas bandas. Per Gynt também aconselhou o sitiante, que possuía uma égua acinzentada, a colocá-la para dar cria. Assim os potros poderiam brincar e galopar pelas colinas e montanhas da região.

Muitos anos depois, o sitiante estava um dia na floresta, perto da época das festas de fim de ano, cortando lenha para o feriado, quando um troll apareceu e perguntou para ele:

- Você ainda tem aquele gatão branco?

- Sim, ainda 'tá deitado lá detrás do forno - disse o homem. - E não é que agora deu cria pra sete filhotes, bem maiores e mais bravos que ele?

- Que desaforo! Então não conte nunca mais com a nossa visita! - exclamou o troll.

$$
* * * * *
$$

- Como Per Gynt nunca teve ninguém, disse Anders. - Ele gostava de contar causos, e cada lorota de dar gosto. Todas aquelas estórias que o pessoal contava que era de antigamente, não é que o danado dava um jeito de dizer que tinha sido com ele?! 
"Det kan nok væra sant, det du sier der," mente Per Fuggelskjellé; "bestemor mi, ho hadde kjent ' $\mathrm{n}, \mathrm{og}$ ho hermde etter 'om meir hell ein gong. Men du, Tor, du kan fel fortælja um den storskyttaren på Vågå som heitte Jens Klomsrud ...
- Realmente, parece ser verdade o que você diz, disse Per Fuggelskjellé. - Minha avó, que havia conhecido Per, sabia imitar ele direitinho. Mas enfim, Tor, você bem que podia contar o causo daquele outro grande caçador em Vaagaa que o pessoal de lá chamava de Jens Klomsrud...

\section{Referências}

ASBJØRNSEN, Per Christen (1848). Norske Huldre-Eventyr og Folkesagn. Christiania. Edição consultada: Norske huldreeventyr og folkesagn fortalt av P. Chr. Asbjornsen. Oslo: Aschehoug, 1934.

BØ, Gudleiv (2006). A dikte Norge. Oslo: Fagbokforlaget.

OLIVEIRA E SILVA, João Rodrigo (2012). Per Gynt: encontros e diálogos com a Psicanálise. Tese de Doutorado. São Paulo: Instituto de Psicologia, USP. 